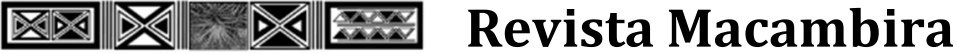

$\begin{array}{cl}\begin{array}{c}\text { Revista Macamhiliả } \\ \text { ISSN:2594-4754 }\end{array} & \begin{array}{l}\text { Laboratório de Políticas Públicas, Ruralidades e Desenvolvimento Territorial (LaPPRuDes) } \\ \text { ARTIGO }\end{array} \\ \text { https://doi.org/10.35642/rm.v4i1.478 }\end{array}$

\section{Actinobactérias no controle do mal das folhas em mudas de}

\section{seringueira}

Carla da Silva Sousa ${ }^{1}$; Aline do Nascimento de Jesus ${ }^{2}$; Francisco de Sousa Lima ${ }^{3}$; Saulo Emílio Almeida Cardoso 4

\begin{abstract}
${ }^{1}$ Doutora em Tecnologias Energéticas e Nucleares. Docente do Instituto Federal de Educação, Ciência e Tecnologia Baiano, Campus Uruçuca. https://orcid.org/0000-0003-4381$\underline{0524}$

${ }^{2}$ Discente do Curso Superior de Tecnologia em Agroecologia do Instituto Federal de Educação, Ciência e Tecnologia Baiano, Campus Uruçuca. https://orcid.org/0000-0001-6138$\underline{7817}$

${ }^{3}$ Doutor em Ciência do Solo. Docente do Instituto Federal de Educação, Ciência e Tecnologia Baiano, Campus Uruçuca. https://orcid.org/0000-0002-2253$\underline{0091}$
\end{abstract}

${ }^{4}$ Biológico. Plantações Michelin da Bahia Ltda. https://orcid.org/00000002-4808-1335

*Autor correspondente: carla.sousa@ifbaiano.edu.br

\section{Resumo:}

A seringueira planta nativa da região Amazônica, é a maior fonte de borracha natural. Entretanto, um dos principais problemas fitossanitários que acomete esta cultura é o mal-das-folhas, causado pelo fungo Microcyclus ulei, que reduz significativamente a produção de látex. Actinobactérias são micro-organismos que apresentam grande potencial como agentes de biocontrole de doenças em plantas, em virtude da produção de antibióticos e enzimas que atuam inibindo a ação de fitopatógenos. Este trabalho teve como objetivo avaliar a eficiência de metabólitos produzidos por isolados de actinobactérias em inibir o crescimento micelial e a germinação de conídios do fungo $M$. ulei in vitro, bem como em reduzir a severidade do mal-das-folhas em mudas de seringueira. Metabólitos produzidos pelos isolados de actinobactérias (ISO-AC 2, ISO-AC 3 e ISO-AC 5) reduziram em até $43,4 \%$ e $77,1 \%$ a germinação de conídios e o crescimento micelial in vitro, respectivamente do fungo $M$. ulei. Todos isolados quando aplicados via pulverização foliar, reduziram a severidade da doença em mudas de seringueira em comparação ao tratamento testemunha (sem aplicação dos metabólitos). Os isolados de actinobactérias testados demonstraram potencial no controle in vitro do fungo M. ulei e do mal-das-folhas em mudas de seringueira.

Palavras-chave: Biocontrole, Microcyclus ulei, Hevea spp.
REVISTA MACAMBIRA

Instituto Federal de Educação, Ciência e Tecnologia Baiano, campus Serrinha. Estrada Vicinal de Aparecida, s/n, Bairro Aparecida, Serrinha (Ba), CEP: 48700-000, sala 01, prédio acadêmico. 


\section{Actinobacteria in the control of leaf disease in rubber tree}

\section{seedlings}

Carla da Silva Sousa1; Aline do Nascimento de Jesus²; Francisco de Sousa Lima3 ; Saulo Emílio Almeida Cardoso ${ }^{4}$

\author{
${ }^{1} \mathrm{PhD}$ in Energy and Nuclear \\ Technologies; Professor at the \\ Federal Institute of Education, \\ Science and Technology Baiano, \\ Campus Uruçuca. \\ https://orcid.org/0000-0003-4381- \\ $\underline{0524}$ \\ ${ }^{2}$ Studant of the Higher Technology \\ Course in Agroecology \\ at the Federal Institute of \\ Education, Science and Technology \\ Baiano, Campus Uruçuca. \\ https://orcid.org/0000-0001-6138- \\ $\underline{7817}$ \\ ${ }^{3} \mathrm{PhD}$ in Soil Science; Professor at \\ the Federal Institute of Education, \\ Science and Technology Baiano, \\ Campus Uruçuca. \\ https://orcid.org/0000-0002-2253- \\ $\underline{0091}$
}

${ }^{4}$ Biologist. Plantações Michelin da Bahia Ltda. https://orcid.org/0000$\underline{0002-4808-1335}$

*Corresponding author: carla.sousa@ifbaiano.edu.br

\begin{abstract}
:
The rubber tree plant native to the Amazon region, is the largest source of natural rubber. However, one of the main phytosanitary problems that affects this crop is the leaf mal, caused by the fungus Microcyclus ulei, which significantly reduces latex production. Actinobacteria are microorganisms that have great potential as biocontrol agents of diseases in plants, due to the production of antibiotics and enzymes that act inhibiting the action of phytopathogens. This study aimed to evaluate the efficiency of metabolites produced by actinobacteria isolates in inhibiting mycelial growth and conidion germination of the fungus $M$. ulei in vitro, as well as in reducing the severity of leaf disease in rubber tree seedlings. Metabolites produced by actinobacteria isolates (ISO-AC 2, ISO-AC 3 e ISO-AC 5) reduced conidia germination and mycelial growth in vitro by up to $43.4 \%$ and $77.1 \%$. All isolates when applied via foliar spray reduced the severity of the disease in rubber tree seedlings compared to the control treatment (without application of metabolites). The isolates of actinobacteria tested showed potential in the in vitro control of the fungus $M$. ulei and leaf disease in rubber tree seedlings.
\end{abstract}

Keywords: Biocontrol, Microcyclus ulei, Hevea spp.

MACAMBIRA JOURNAL

Federal Institute of Education, Science and Technology Baiano, campus Serrinha. Estrada Vicinal de Aparecida, s/n, Bairro Aparecida, Serrinha, Bahia, Brasil, CEP: 48700-000, sala 01, prédio acadêmico. 


\section{Introdução}

A cultura da seringueira [Hevea brasiliensis (Willd. ex A. Juss.) Müll. Arg.] é explorada mundialmente por ser fonte natural de borracha, trazendo benefícios socioeconômicos, como geração de empregos e renda. Além disso, representa uma alternativa à utilização de fontes não renováveis na fabricação da borracha sintética, como o petróleo (CORNISH, 2001).

Entretanto, o insucesso da heveicultura nas áreas tradicionais de cultivo no Brasil surgiu principalmente em virtude do aparecimento do mal-das-folhas, doença causada pelo M. ulei Henn. Von (Arx) (anamorfo: Pseudocercospora ulei Kuyper), fungo originário da Amazônia, e que se encontra presente em todas as regiões heveícolas do país (MATTOS et al., 2003; MORAES; MORAES, 2008; GASPAROTTO; PEREIRA, 2012). Em plantas novas, o mal-das-folhas provoca desfolhamento e afeta o crescimento, enquanto que, nas árvores adultas, ocorre menor produção de látex e mortalidade (GONÇALVES; MONTEIRO, 2007).

Diversos estudos foram realizados visando o controle da doença e expansão da heveicultura, contudo, sem a obtenção de resultados satisfatórios. Foi realizado o melhoramento genético para a obtenção de clones de seringueira resistentes e produtivos, entretanto, este método foi ineficiente em virtude do fungo M. ulei possuir elevada capacidade de mutação, resultando em quebra de resistência (SOUSA; MORAES, 2001; MATTOS, 2003). Foram também realizados alguns trabalhos avaliando a substituição de copas susceptíveis por clones de copas resistentes, contudo, houve problemas com adoção da técnica de enxertia tais como: baixo índice de pegamento, redução da produtividade de borracha e aumento do custo de produção (MORAES; MORAES, 2008).

Trabalhos desenvolvidos, utilizando o fungo Dicyma pulvinata no controle biológico, apresentaram-se como uma alternativa viável no controle do mal-das-folhas na cultura da seringueira (MELO et al., 2008, DELMADI et al., 2009). O controle biológico por micro-organismos no controle de fitopatógenos resulta na redução ou eliminação do uso de agroquímicos (LANA FILHO et al., 2016).

Estudos demonstraram o potencial das actinobactérias como agentes de controle biológico de fitopatógenos em culturas de interesse econômico (SOLTANZADEH et al., 2016; GOMES et al., 2018; HAO et al., 2020). As actinobactérias, particularmente o gênero Streptomyces, são reconhecidas pelo seu potencial em produzir uma vasta quantidade de metabólitos secundários, dentre os quais se destacam as substâncias antibióticas (ANZAI et al., 2008; BARRETO et al., 2008; DURAIPANDIYAN et al., 2010; MIYAUCHI, 2012). No solo, estas bactérias realizam funções importantes no processo de ciclagem de nutrientes, degradando compostos complexos de difícil decomposição como lignocelulose, lignina, celulose e outros materiais recalcitrantes, devido à sua capacidade em produzir diversas enzimas hidrolíticas e lipolíticas (OLIVEIRA et al., 2017). 
O objetivo deste trabalho foi avaliar a eficiência de isolados de actinobactérias no controle do mal-das-folhas em mudas de seringueira. A seringueira é uma espécie arbórea cultivada em sistemas agroflorestais, pois além da importância econômica na extração do látex, fornece madeira e sombreamento para animais e cultivos agrícolas, sendo, portanto, uma alternativa interessante em sistemas agroecológicos de produção agrícola. O controle biológico com o uso de actinobactérias é uma importante ferramenta a ser utilizada no manejo de doenças em sistemas agroecológicos de produção, uma vez que, esta tecnologia reduz a contaminação de alimentos, os custos de produção e os impactos negativos no ambiente em comparação aos agrotóxicos.

\section{Material e métodos}

\section{Obtenção de metabólitos de actinobactérias}

Foram avaliados isolados de actinobactérias (ISO-AC 2, ISO-AC 3 e ISO-AC 5) obtidos de solo rizosférico de plantas de seringueira sadias. Inicialmente, os isolados de actinobactérias foram cultivados em meio de cultura amido caseína por 8 dias. Após este período, discos de $7 \mathrm{~mm}$ foram retirados das bordas das colônias e transferidos para Erlenmeyers contendo $200 \mathrm{ml}$ de meio de cultura caldo TSB, e incubados a temperatura ambiente, durante 14 dias. Em seguida, o meio foi centrifugado a $3500 \mathrm{rpm}$ por 30 minutos e o sobrenadante contendo metabólitos produzidos pelos isolados de actinobactérias coletado e armazenado em freezer a $-4^{\circ} \mathrm{C}$.

\section{Obtenção de suspensão de conídios}

Para obtenção de inoculo, o fungo M. ulei foi multiplicado em meio de cultura sólido com água de coco verde (MATTOS, 1999), e as placas de Petri contendo o meio de cultura incubadas em temperatura ambiente durante 5 dias. Após este período, foram adicionados $20 \mathrm{ml}$ de água destilada nas placas, e em seguida, realizada a raspagem de colônias crescidas, com auxílio de um pincel. Em seguida, a suspensão obtida foi filtrada em gaze esterilizada.

\section{Inibição da germinação de conídeos e do crescimento micelial do fungo M. ulei}

Bioensaio 1: Para avaliar a eficiência dos metabólitos de actinobactérias em inibir a germinação de conídios do fungo M. ulei, foram adicionados $40 \mu$ da suspensão de conídios na concentração 2 x $10^{5}$ conídios/ml, juntamente com 40 4 l de metabólitos dos isolados de actinobactérias em lâminas escavadas. As lâminas foram incubadas em câmara úmida formada por placas de Petri esterilizadas, contendo no fungo papel de filtro esterilizado e umedecido, vedadas com parafilme em temperatura ambiente. O 
tratamento controle consistiu de água destilada e conídios do fungo M. ulei. Quando o tratamento controle apresentou $50 \%$ de conídeos germinados (aquele cujo tubo germinativo apresentou comprimento superior ao dobro do diâmetro do conídio), os tratamentos (ISO-AC 2, ISO-AC 3 e ISOAC 5) com metabólitos das actinobactérias receberam 01 gota de lactofenol azul para paralisar a germinação dos conídios. A contagem do número de conídios germinados foi realizada com auxílio de um microscópio biológico binocular com aumento de $40 \mathrm{X}$, através da contagem aleatória de 100 esporos. O bioensaio foi conduzido em delineamento experimental inteiramente casualizado, sendo avaliados três isolados de actinobactérias, com três repetições.

Bioensaio 2: Para avaliar a eficiência dos isolados de actinobactérias em inibir o crescimento micelial do fungo M. ulei, foram adicionados dois discos de $7 \mathrm{~mm}$ (fungo e do isolado de actinobactérias) em lados equidistantes de placa de Petri contendo meio de cultura BDA. O tratamento controle consistiu de placas contendo somente disco do fungo sem os isolados de actinobactérias. Os discos foram retirados da borda de uma cultura do fungo após 8 dias de crescimento. O crescimento micelial do fungo foi medido diariamente com auxílio de uma régua milimétrica. O bioensaio foi conduzido em delineamento experimental inteiramente casualizado, sendo avaliados três isolados de actinobactérias, com três repetições.

\section{Controle do mal-das-folhas em mudas de seringueira}

Para avaliar o efeito de metabólitos produzidos pelos isolados de actinobactérias no controle do mal das folhas em mudas de seringueira, foi instalado um experimento em condições de casa de vegetação, em delineamento experimental inteiramente casualizado, esquema fatorial, $(3 \times 2)+1$, sendo três isolados de actinobactérias (ISO-AC 2, ISO-AC 3 e ISO-AC 5), duas formas de inoculação (pulverização foliar e irrigação do solo), e uma testemunha (sem adição dos isolados de actinobactérias, plantas pulverizadas ou irrigadas com água) com 15 repetições. Inicialmente, os isolados de actinobactérias foram transferidos para Erlenmeyers contendo $200 \mathrm{ml}$ meio de cultura caldo TSB, e em seguida incubados a temperatura ambiente, durante 14 dias. Após esse período, foi realizada a centrifugação do meio a $3500 \mathrm{rpm}$ por 30 minutos e o sobrenadante contendo metabólitos produzidos pelos isolados coletado e armazenado em freezer a $-4^{\circ} \mathrm{C}$. Mudas de seringueira sadias do clone FX 3864 , foram inoculadas com $100 \mathrm{ml}$ dos metabólitos (via pulverização foliar e via irrigação do solo) Figura 1. Após 5 dias, as mudas foram inoculadas com uma suspensão aquosa contendo 2 x $10^{5}$ conídios/ml de M. ulei, agente causador do mal-das-folhas. 
Figura 1. Inoculação das mudas de seringueira com metabólitos produzidos pelos isolados de actinobactérias via pulverização foliar (a) e via irrigação do solo (b).
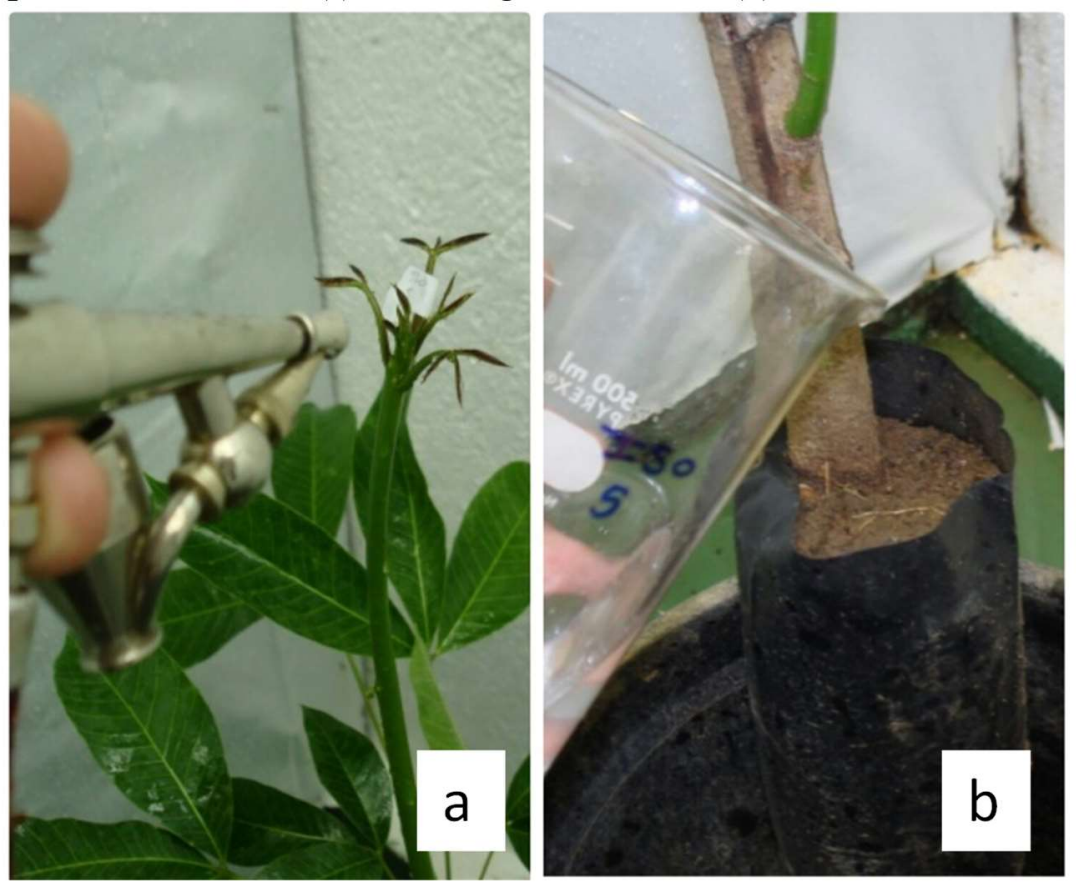

A inoculação via foliar foi realizada em câmara úmida com temperatura variando de 23 a $26^{\circ}$ e umidade superior a 95\%, com o auxílio de um atomizador na face inferior dos folíolos jovens e de coloração violeta, correspondentes ao estágio B2, conforme descrito por Hallé \& Martin (1968). Após a inoculação (via pulverização foliar e irrigação do solo), as mudas permaneceram 24 horas no escuro, e posteriormente foram mantidas em regime de 12 horas no escuro e 12 horas no claro por 12 dias. Após este período, foi utilizada escala diagramática modificada proposta por Gasparotto et al., (1989), para avaliar o mal-das-folhas nas mudas da seringueira, sendo: (0) Sem sintoma; (1) Lesões necróticas sem esporos; (2) Lesões não necróticas sem esporos; (3) Esporulação muito fraca sobre a face inferior da lesão; (4) Esporulação forte cobrindo parcialmente a face inferior da lesão; (5) Esporulação muito forte cobrindo toda a face da lesão; (6) Esporulação muito forte cobrindo toda a face inferior da lesão e forte na face superior.

\section{Análise estatística}

Os dados obtidos foram submetidos a análise de variância (ANOVA) e as médias entre os tratamentos comparadas com Scott \& Knott a 5\% de probabilidade.

\section{Resultados e discussão}


O tratamento testemunha apresentou maior percentagem de conídios germinados, diferindo estatisticamente dos demais tratamentos (Tabela 1). Nos tratamentos utilizando metabólitos dos isolados de actinobactérias (ISO-AC 2, ISO-AC 3 e ISO-AC 5) houve redução de respectivamente, 56,6\%, 52,5\% e 25,0\% na germinação de conídios do fungo M. uley em comparação ao tratamento testemunha.

Quando avaliada a percentagem de conídios não germinados, observa-se que não houve diferença estatística entre os ISO-AC $2(38,6 \%)$ e ISO-AC 5 (46,4\%), que foram superiores ao tratamento controle, onde foram registrados apenas $20,4 \%$ de conídios não germinados (Tabela 1). Estudo realizado por Soares et al., (2009) demonstrou que isolados de actinobactérias promoveram redução de 94,1\% e 94,4\%, respectivamente na germinação de esporos dos fungos Cladosporium fulvum Cooke e Fusarium oxysporum $\mathrm{f}$. sp. lycopersici fitopatógenos que atacam a cultura do tomateiro.

Tabela 1. Efeito de metabólitos produzidos pelos isolados de actinobactérias na germinação de esporos e no crescimento micelial do fungo Microcyclus ulei

\begin{tabular}{cccc}
\hline Isolados de & \multicolumn{2}{c}{ Número de conídios } & Crescimento micelial \\
\cline { 2 - 3 } actinobactérias & Germinados & Não germinados & $(\%)$ \\
\hline Controle & $39,2 \mathrm{a}$ & $20,4 \mathrm{c}$ & $2,42 \mathrm{a}$ \\
ISO-AC 2 & $18,6 \mathrm{~b}$ & $35,8 \mathrm{~b}$ & $1,92 \mathrm{~b}$ \\
ISO-AC 3 & $17,0 \mathrm{~b}$ & $38,6 \mathrm{a}$ & $2,30 \mathrm{a}$ \\
ISO-AC 5 & $29,4 \mathrm{~b}$ & $46,4 \mathrm{a}$ & $2,02 \mathrm{~b}$ \\
\hline
\end{tabular}

Letras iguais na coluna não diferem estatisticamente entre si pelo teste de Scott \& Knott a 5\% de probabilidade

O cultivo pareado com ISO-AC 5 e ISO-AC 2, promoveu redução no crescimento micelial do fungo M. uley (Figura 1). Não houve efeito significativo do ISO-AC 3 sobre crescimento micelial do fungo. Alves et al., (2013) observaram que isolados de actinobactérias reduziram em até 66,9\% o crescimento micelial de Fusarium verticillioides causador de doenças em sementes de milho. Isolados de actinobactérias promoveram redução do crescimento micelial e germinação de esporos in vitro de Colletotrichum gloeosporioides e Curvularia eragrostides, ambos fitopatogênicos da cultura do inhame (Soares et al., 2006).

Diversos mecanismos são utilizados pelos isolados de actinobactérias que podem inibir a germinação de esporos e/ou o crescimento micelial de fungos fitopatogênicos. Dentre estes mecanismos, pode-se citar, por exemplo, a produção de enzimas como quitinases e 1,3 $\beta$ glucanases (SILVA et al., 2012). Estas enzimas atuam na degradação da parede celular de fungos que na maioria das vezes é composta principalmente de quitina e glucana, impedindo o crescimento fúngico, colonização do tecido vegetal e progresso da doença. Além de enzimas, estes micro-organismos também são produtores de substâncias antimicrobianas como os antibióticos (DURAIPANDIYAN et al., 2010), que impedem que o fitopatógeno colonize o tecido vegetal e ocasione o surgimento da doença. 
Comparando cada método de inoculação entre os isolados (colunas de cores iguais), verifica-se que, independente do isolado, as mudas de seringueira inoculadas via pulverização foliar, apresentaram menor severidade do mal-das-folhas em comparação às mudas do tratamento controle. Mudas inoculadas via irrigação do solo com metabólitos do isolado ISO-AC 5 não diferiram estatisticamente das mudas do tratamento controle, entretanto, mudas inoculadas com metabólitos dos isolados ISO-AC 2 e ISO-AC 3 , apresentaram redução da severidade do mal-das-folhas (Figura 1).

Figura 1. Severidade do mal-das-folhas em mudas de seringueira inoculadas com metabólitos produzidos pelos isolados de actinobactérias. Letras iguais não diferem estatisticamente pelo teste de Scott e Knott a $5 \%$ de probabilidade. Letras maiúsculas comparam colunas de cores diferentes e letras minúsculas comparam colunas de cores iguais.

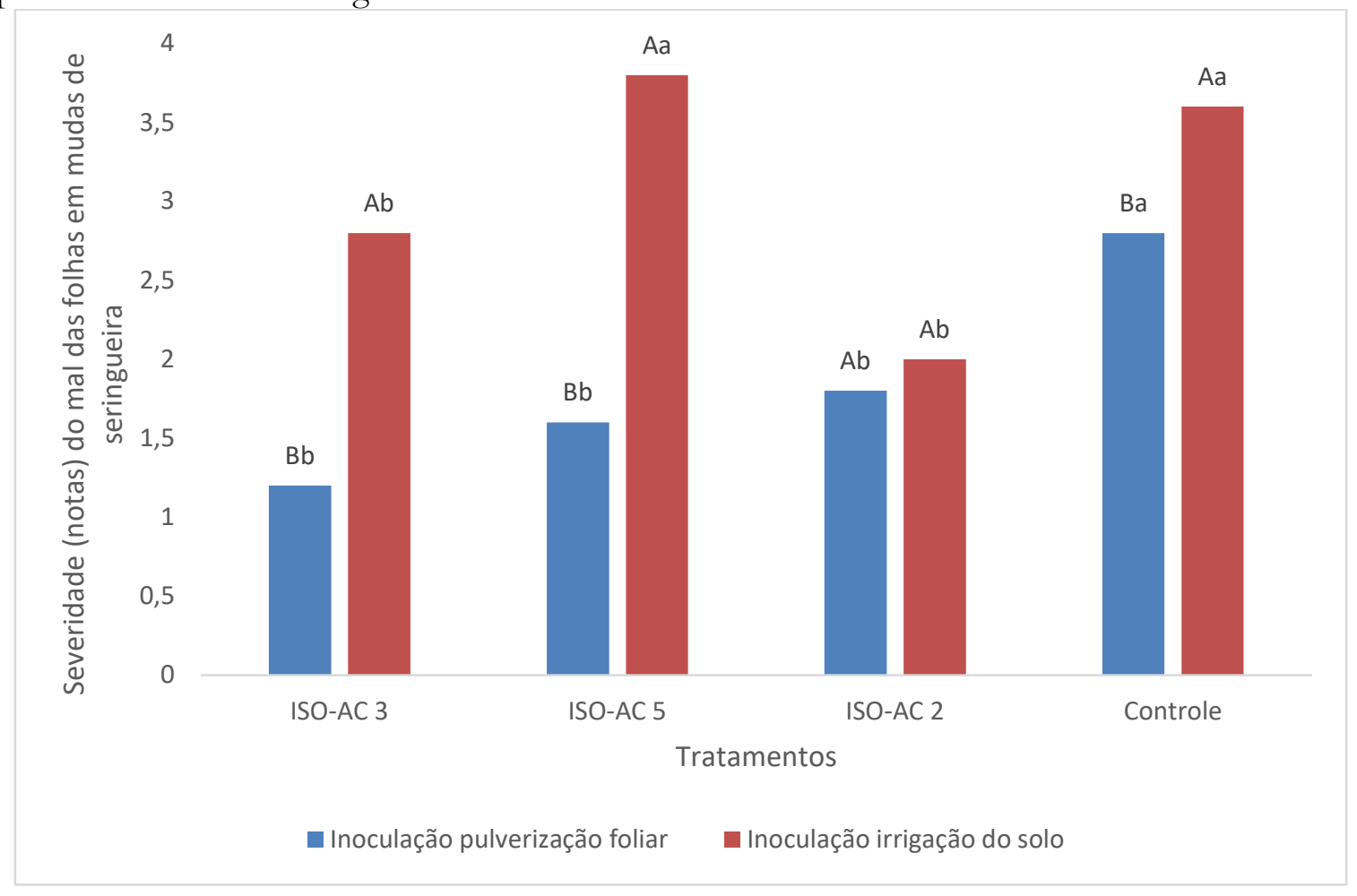

O controle biológico tem se demonstrado uma alternativa promissora no controle do mal-dasfolhas na cultura da seringueira. Estudos realizados com o fungo D. pulvinata demonstraram resultados satisfatórios (Melo et al., 2008, Delmadi et al., 2009). As actinobactérias são micro-organismos do solo com grande potencial para atuarem no controle de fitopatógenos que atacam culturas de interesse econômico. Estes micro-organismos podem, através da produção de enzimas e antibióticos, inibir os fitopatógenos, e consequentemente o estabelecimento destes nos tecidos vegetais e o desenvolvimento da doença. Além disso, quando em contato com as plantas, actinobactérias podem ativar a resistência sistêmica induzida, ou seja, os próprios mecanismos de defesa vegetal contra o ataque de agentes fitopatogênicos. 
Comparando os métodos de inoculação entre cada isolado (colunas de cores diferentes), verificase que, com exceção do ISO-AC 2, mudas inoculadas via pulverização foliar apresentaram menor severidade da doença, em comparação às mudas inoculadas via irrigação do solo. Possivelmente, quando aplicados nas folhas, dependendo das condições climáticas, da textura do tecido foliar e da microbiota presente no filoplano, os metabólitos podem ser perdidos para o ambiente, não permanecendo tempo suficiente para desenvolver ação contra o fungo M. ulei que foi aplicado posteriormente. No entanto, a aplicação via irrigação do solo, possibilita maior superfície de contato e maior tempo de interação entre os metabólitos e as raízes das plantas. Além disso, os metabólitos aplicados no solo são moléculas orgânicas que servem de substrato alimentar para outros organismos que atuam no biocontrole de doenças.

\section{Conclusões}

1. Metabólitos produzidos pelos isolados de actinobactérias testados reduziram in vitro a germinação de conídios e o crescimento micelial do fungo Microcyclus ulei;

2. Metabólitos produzidos pelos isolados de actinobactérias reduziram a severidade do mal-dasfolhas em mudas de seringueira;

3. A inoculação dos metabólitos de actinobactérias via irrigação do solo é mais efetiva que a inoculação dos metabólitos via pulverização foliar; e

4. Estudos futuros devem ser realizados avaliando épocas de aplicação dos metabólitos, concentração dos metabólitos, diferentes isolados de actinobactérias e idade das mudas de seringueira;

5. A realização de práticas agroecológicas em sistemas de cultivo como a rotação de culturas, policultivo e adubação orgânica estimulam micro-organismos benéficos presentes no solo a exemplo das actinobactérias.

\section{Agradecimentos}

Os autores agradecem ao Instituto Federal de Educação, Ciência e Tecnologia Baiano - IFBaiano pelo financiamento do projeto aprovado na Chamada Interna PROPES N¹0/2013 e à concessão de bolsa de produtividade à profa. Dra. Carla da Silva Sousa e a empresa Plantações Michelin da Bahia Ltda pelo suporte na realização do experimento em casa de vegetação através do fornecimento das mudas de seringueira e apoio do técnico Luciano Santos da Conceição. 


\section{Referências bibliográficas}

ALVES, E. N. T. D.; MARRIEL, I. E.; OLIVEIRA, C. A.; COSTA, R. V.; COTA, L.V.; SILVA, D. D.; MATTOS, B. B.; VERDOLIN, A. L. G. Seleção de micro-organismos antagonistas para biocontrole de Fusarium verticillioides na cultura do milho (Zea mays L.). Sete Lagoas: Embrapa Milho e Sorgo, 2013, 26 p. (Boletim de Pesquisa e Desenvolvimento, 75).

ANZAI, K.; NAKASHIMA, T.; KUWAHARA, N.; SUZUKI, R.; OHFUKU, Y.; TAKESHITA, S.; ANDO, K. Actinomycete bacteria isolated from the sediments at coastal and offshore area of Nagasaki prefecture, Japan: diversity and biological activity. Journal of Bioscience and Bioenginering, v.106, p. 215-217. 2008 .

BARRETO, T. R.; SILVA, A.C.M.; SOARES, A.C.F.; SOUZA, J. Population densities and genetic diversity of actinomycetes associatedto the rhizosphere of Theobroma cacao. Brazilian Journal of Microbiology, v. 39, p. 464- 470, 2008.

CORNISH, K. Similarities and differences in rubber biochemistry among plant species. Phytochemistry, v.57, p.1123-1134, 2001.

DELMADI, L.C.; CASSETARI NETO, D.; ROCHA, V.F. Avaliação do potencial de uso do hiperparasita Dicyma pulvinata (Berk. \& M. A. Curtis) no controle biológico do mal-das-folhas [Microcyclus ulei (Henn.) Arx] de seringueira [Hevea brasiliensis (Wild. ex A. Juss.) Muell. Arg.] em São José do Rio Claro MT. Ciência Florestal, v.19, n.2, p.183-193, 2009.

DURAIPANDIYAN, V.; SASI, A.H.; ISLAM, V.I.H.; VALANARASU, M.; IGNACIMUTHU, S. Antimicrobial properties of actinomycetes from the soil of Himalaya. Journal of Medical Mycology, v. 20, p.15-20, 2010

GASPAROTTO, L.; PEREIRA, J.C.R. Doenças da seringueira no Brasil. Brasília: Embrapa, 2012. 255p.

GASPAROTTO, L.; ZAMBOLIM, L.; MAFFIA, L.A.; VALE, F.X.R.; JUNQUEIRA, N.T.V. Efeito da temperatura e umidade sobre a infecção de seringueira (Hevea spp.) por Microcyclus ulei. Fitopatologia Brasileira, v.14, p.38-41, 1989.

GOMES, E.B.; DIAS, L.R.L.; MIRANDA, R.C.M. Actinomycetes bioactive compounds: Biological control of fungi and phytopathogenic insect. African Journal of Biotecnology, v.17, p. 552-559, 2018.

GONÇALVES, A.O.; MONTEIRO, L.L. Seringueira: novas tecnologias de produção. Aptidão climática para a cultura da seringueira no estado de Minas Gerais. v.28, n.237, p.39-43, 2007 (Informe Agropecuário).

HALLÉ, F.; MARTIN, R. Étude de la croissance rythmique chez l'hévéa (Hevea brasiliensis Müll. Arg., Euphorbiacées, Crotonoïdées). Adansonia, v. 8, p.475-503. 1968.

HE, H.; HAO, X.; ZHOU, W.; SHI, N.; FENG, J.; HAN L. Identification of antimicrobial metabolites produced by a potential biocontrol Actinomycete strain A217, Journal of Applied Microbiology, v. 128, n.4, p. 1143-1152, 2020.

MATTOS, C.R.R. Meios de cultura com água de coco verde para esporulação de Microcyclus ulei. Fitopatologia Brasileira, v. 24, p.470. 1999. (Suplemento).

MATTOS, C.R.R.; GARCIA, D.; PINARD, F.; LE GUEN, V. Variabilidade de isolados de Microcyclus ulei no Sudeste da Bahia. Fitopatologia Brasileira, v.28, p.502-507, 2003. 
MELO, D.F.; MELLO, S. C. M.; MATTOS, C.R.R.; CARDOSO, S.E.A. Compatibilidade de Dicyma pulvinata com defensivos agrícolas e eficiência do biocontrole do mal-das-folhas da seringueira em campo. Pesquisa Agropecuária Brasileira, v.43, n.2, p.179-185, 2008.

MIYAUCHI, M.Y.H., 2012. Biocontrole de fungos patogênicos por actinobactérias isoladas de rizosfera de Araucaria angustifolia. Tese (Doutorado em Microbiologia Agrícola). Piracicaba, ESALQ.

MORAES, V.H.F.; MORAES, L.A.C. Desempenho de clones de copa de seringueira resistentes ao maldas-folhas. Pesquisa Agropecuária Brasileira, v.43, n.11, p.1495-1500, 2008.

OLIVEIRA, S.M.; SILVA, D.F.; SANTOS, I.N.; CORREIA C.V.P.; LIBERAL, T.C.F.; BRANCO, L.C. COLARES, C.N.J.; ESCHER, S.K.S.; ISHIDA, J.K.; MUI, T.S.; ARAÚJO, J.M.; AMORIM, J.M. Prospecção de enzimas de interesse industrial produzidas por actinobactéria isolado de solo na Amazônia. Scientia Plena, v. 13, n. 3, p. 1-6, 2017.

SILVA, K.; CASSETARI, A. S.; LIMA, A. S.; BRANDT, E.; PINNOCK, E.; VANDAMMEC, P.; MOREIRA, F. M. S. Diazotrophic Burkholderia species isolated from the Amazon region exhibit phentypical, functional and genetic diversity. Systematic and Applied Microbiology, v.35, p.253-262, 2012.

SOARES, A.C.F., SOUSA, C. S., GARRIDO, M.S. Antagonism of streptomycetes against Cladosporium fulvum Cooke and Fusarium oxysporium sp. Lycopersici. Ciência Rural, v.39, p.1897 - 1900, 2009.

SOARES, A.C.F.; SOUSA, C. S., GARRIDO, M. S.; PEREZ, J.O.; ALMEIDA, N.S. Streptomycetes with in vitro activity against the yam pathogens Curvularia eragrostides and Colletotrichum gloeosporioides. Brazilian Journal of Microbiology, v.37, p.456 - 461, 2006.

SOLTANZADEH, M.; NEJAD, M.S.; BONJAR, G.H.S. Application of soil-borne actinomycetes for biological control against Fusarium wilt of chickpea (Cicer arietinum) caused by Fusarium solani fsp pisi. Journal of Phytopatology, v. 164, n. 11-12, p. 967-978, 2016.

SOUSA, N.R.; MORAES, V.H.F. Recursos genéticos de Hevea. In: SOUSA, N.R.; SOUZA, A. das G.C. (Ed.). Recursos fitogenéticos na Amazônia Ocidental; conservação, pesquisa e utilização. Manaus: Embrapa Amazônia Ocidental, 2001. p.189-199. 


\begin{tabular}{|c|c|}
\hline Informações do Artigo & Article Information \\
\hline Recebido em: 17/06/2020 & Received on: $17 / 06 / 2020$ \\
\hline Aceito em: 20/07/2020 & Accepted in: 20/07/2020 \\
\hline Publicado em: 30/07/2020 & Published on: $30 / 07 / 2020$ \\
\hline $\begin{array}{l}\text { Conflitos de Interesse: Os autores declaram não } \\
\text { haver quaisquer conflitos de interesse referente a } \\
\text { este artigo. }\end{array}$ & Conflict of Interest: No reported. \\
\hline Como citar este artigo & How to cite this article \\
\hline $\begin{array}{l}\text { Sousa, C. S.; Jesus, A. N.; Lima, F. S.; Cardoso, S. } \\
\text { E. A. (2020). Actinobactérias no controle do mal } \\
\text { das folhas em mudas de seringueira. Revista } \\
\begin{array}{lll}\text { Macambira, } & 4(1), & \text { e } 041007 . \\
\text { https://doi.org/10.35642/rm.v4i1.478 }\end{array}\end{array}$ & $\begin{array}{l}\text { Sousa, C. S.; Jesus, A. N.; Lima, F. S.; Cardoso, S. } \\
\text { E. A. (2020). Actinobacteria in the control of leaf } \\
\text { disease in rubber tree seedlings. Revista } \\
\begin{array}{l}\text { Macambira, } 4(1), \\
\text { https://doi.org/10.35642/rm.v4i1.478 }\end{array}\end{array}$ \\
\hline 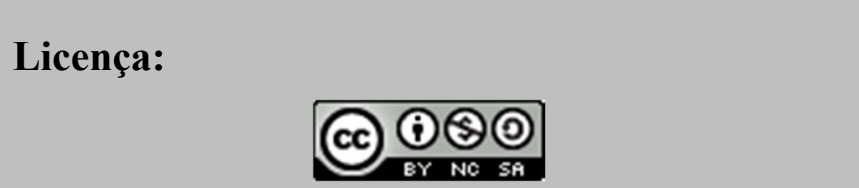 & (c) (i) (-) \\
\hline $\begin{array}{l}\text { Este trabalho está licenciado sob uma Licença } \\
\text { Internacional Creative Commons Attribution- } \\
\text { NonCommercial-ShareAlike } 4.0 \text { International. }\end{array}$ & $\begin{array}{l}\text { This work is licensed under a Creative Commons } \\
\text { Attribution-NonCommercial-ShareAlike } \\
\text { International License. }\end{array}$ \\
\hline
\end{tabular}

